OPEN ACCESS

Edited by:

Maw Pin Tan,

University of Malaya, Malaysia

Reviewed by:

Antony Bayer,

Cardiff University, United Kingdom Jennifer Albrecht, University of Maryland, United States

*Correspondence: Jacob J. Sosnoff jsosnoff@illinois.edu

Specialty section:

This article was submitted to Geriatric Medicine,

a section of the journal

Frontiers in Medicine

Received: 07 August 2018 Accepted: 05 March 2019 Published: 27 March 2019

Citation:

Wood TA, Morrison S and Sosnoff JJ (2019) The Role of Neck Musculature in Traumatic Brain Injuries in Older Adults: Implications From Sports Medicine. Front. Med. 6:53. doi: 10.3389/fmed.2019.00053

\section{The Role of Neck Musculature in Traumatic Brain Injuries in Older Adults: Implications From Sports Medicine}

\author{
Tyler A. Wood ${ }^{1}$, Steven Morrison ${ }^{2}$ and Jacob J. Sosnoff ${ }^{1 *}$ \\ ${ }^{1}$ Department of Kinesiology and Community Health, University of Illinois at Urbana-Champaign, Urbana, IL, United States, \\ ${ }^{2}$ School of Physical Therapy and Athletic Training, Old Dominion University, Norfolk, VA, United States
}

Traumatic brain injuries (TBIs) are common and serious injuries to older adults. The majority of TBls in older adults are sustained when the head impacts the ground or other surface during a fall. While several non-modifiable risk factors have been identified for fall-related TBls in older adults, there still remains a dearth of knowledge surrounding modifiable risk factors. Thus, this significant knowledge gap warrants an investigation into research across disciplines. The sports medicine literature has examined several modifiable risk factors to prevent a mild form of TBI known as concussion. While this research has identified several risk factors, one particular risk factor may have potential implications to fall-related TBls in older adults. The sports medicine literature has shown that decreased neck strength and slower neck muscle activation are significant predictors for sports-related concussion. Similarly, older adults experience age-related declines to neck muscle strength and muscle activation. Consequently, these age-related declines to the neck musculature may result in the inability of older adults to control their head during a fall, which results in greater impact forces being transmitted to the brain and increases the risk of TBI. This perspective article assesses the sports medicine literature related to the implications of neck strength and muscle activation in sports-related concussion, discusses age-related declines to neck strength and muscle activation, and highlights the potential impact of the neck musculature on fall-related TBls in older adults.

Keywords: accidental falls, head movements, neck muscles, older adults, traumatic brain injury

\section{INTRODUCTION}

Traumatic brain injuries (TBIs) are induced by biomechanical forces that are transmitted to the brain after a direct blow to the head, face, neck, or body (1). In 2013, the Centers for Disease Control and Prevention reported that there were approximately 2.8 million TBIs that resulted in emergency department visits, hospitalizations, and/or deaths in the United States (1). Furthermore, the rate of TBIs in older adults almost doubled between 2007 and 2013 (1). For older adults, the health consequences of a TBI are more marked with extended hospitalizations and a $>10 \%$ fatality rate (2). Upwards of $80 \%$ of TBIs in older adults are a result of the head hitting the ground or other surface during a fall (2).

There is little doubt that fall-related TBIs are a major cause of morbidity and mortality in older adults (1-3). Several investigations have identified non-modifiable risk factors, such as 
gender and age, as major mitigating factors in fall-related head injuries (1-7) However, despite our understanding of the significance of this problem, there has been limited research examining modifiable risk factors of fall-related TBIs in older adults (1-7). One report concluded that older adults should attempt to avoid fall-related head impact but provided minimal insight on how to accomplish this feat (4).

As there is minimal information on modifiable risk factors for fall-related TBIs in older adults, it is worthwhile to examine research across disciplines for insight. The sports medicine literature has focused on the prevention of a mild form of TBI, known as concussion (8). Indeed, it has been estimated that young adults experience approximately 1.6-3.8 million sportsrelated concussions each year in the United States (9). The sports medicine literature has examined several potentially modifiable risk factors including the use of protective equipment, rules and legislation governing sport, and implications of the neck musculature $(8,10,11)$. While the majority of modifiable risk factors may not pertain to older adults, the implications of the neck musculature as it relates to sports-related concussion may provide valuable information.

Prior to discussing the implications of neck musculature for mild TBI, it is important to understand the location and action of the primary movers of the neck musculature. The neck

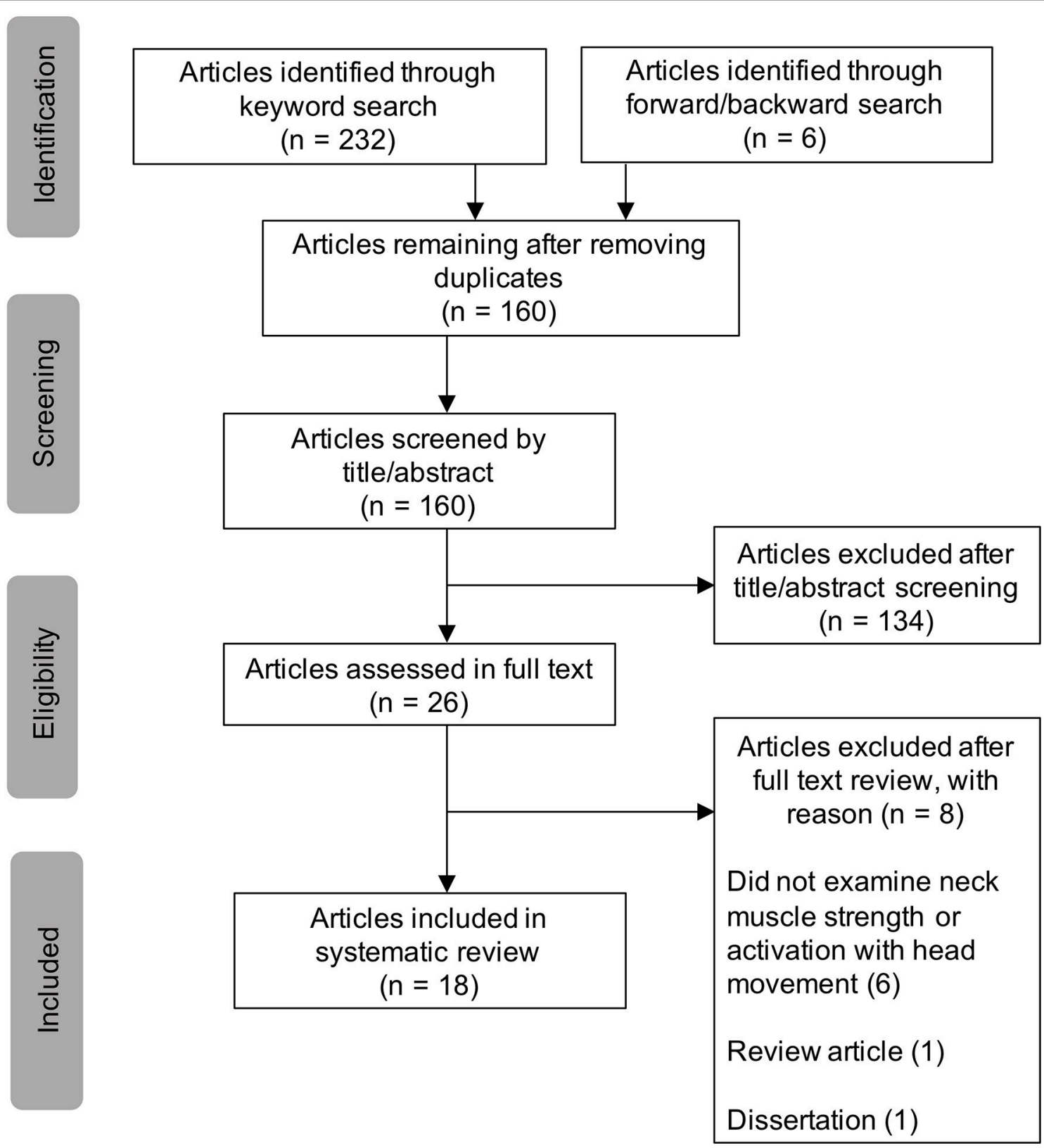

FIGURE 1 | Study selection flowchart. 
musculature consists of sternocleidomastoids (SCM), splenius capitis, and upper trapezius muscle (12). The SCM originates on the manubrium and the medial end of the clavicle; it then inserts on the mastoid process $(12,13)$. Unilateral activation of the SCM results in lateral flexion while bilateral activation results in neck flexion occurs $(12,13)$. The splenius capitis originates on the lower half of the ligamentum nuchae and spinous processes of C7-T3. Unilateral activation of the splenius capitis results in lateral flexion while bilateral activation results in neck extension. The trapezius is the most superficial muscle in the back. It originates from the superior nuchal line, external occipital protuberance, ligamentum nuchae, and the spinous processes of C7 to T12 $(12,13)$. The upper trapezius extends the neck, along with contributing to lateral flexion and rotation $(12,13)$. There are many other deep muscles located on the posterior and lateral sides of the neck and attach to individual vertebrae (12). These smaller muscles are beyond the scope of this review.

In general, the activation of the neck musculature has been shown to decrease head acceleration and potentially prevent sports-related concussions $(11,14-30)$. Specifically, it has been demonstrated that decreased neck strength and slower activation of the neck muscles are a significant predictor for sports-related concussion. Empirical data has also revealed that stronger neck muscles and faster muscle activation mitigates forces at head impact $(11,16,31)$.

Although it would be logical to speculate that neck strength and muscle activation are related to the magnitude of head acceleration experienced during a fall and TBI in older adults, there is a dearth of evidence. Thus, the purpose of this perspective article is to examine the sports medicine literature surrounding the implication of neck strength and muscle activation in sportsrelated concussion, discuss age-related changes to neck strength and muscle activation, and highlight the potential impact on fall-related TBIs in older adults.

\section{LITERATURE SEARCH}

A keyword search was performed in PubMed, Cumulative Index to Nursing and Allied Health Literature (CINAHL), Web of Science, and Ovid-Medline. The search algorithm included all possible combinations of the keywords from the following three groups: (1) "concussion," "traumatic brain injury," and "head injury;" (2) "neck" and "cervical;" and (3) "muscle strength," "muscle activation," and "impact velocity." A reference list search (i.e., backward reference search) and cited reference search (i.e., forward reference search) were also conducted based on the full-text articles that met the study selection criteria that were identified from the keyword search. Articles identified from the backward and forward reference search were further screened and evaluated using the same study selection criteria. Reference searches were repeated on all newly identified articles until no additional relevant articles were found. Articles published up to March 10, 2018 were identified.

Studies that met all the following criteria were included in the review: study design: randomized controlled trial, case control study, cohort study, pre-post-study, or cross-sectional study; study subjects: human male and female participants of all ages; main outcome: neck strength and neck activation related to head movement or control and TBIs; article type: peer-reviewed publication; and language: English.

T. Wood conducted the literature search. Figure 1 displays the study selection flowchart. A total of 160 unduplicated articles were identified through the keyword and reference search, by which 134 articles were excluded by title and abstract screening. Twenty-six articles were assessed in full texts, in which 18 articles were identified and included in the review (11, 14-30). Eight articles were excluded after full text review. Six studies were excluded because they did not examine neck strength or activation with head movement (32-37). One study was excluded because it was a review (38) and another was excluded because it was a dissertation (39). Table 1 reports the basic characteristics of each of the included studies.

\section{NECK STRENGTH AND MUSCLE ACTIVATION IMPLICATIONS IN OLDER ADULTS}

\section{Neck Strength as Risk Factor for Fall-Related TBI}

Neck strength is a significant predictor of concussions in high school athletes. In a large epidemiological study of 6,704 high school athletes, Collins et al. (11) reported that lower overall neck strength was a significant predictor of sportsrelated concussion. Within this investigation of 6,704 high school athletes, researchers utilized a valid and reliable handheld tension scale to measure strength in neck flexion, extension, and right/left lateral flexion. An average of the four strength measures was utilized in analysis. This finding was supported by several smaller investigations utilizing various measures of neck strength, which empirically revealed that greater neck strength resulted in significantly less head acceleration in response to perturbations in young athletes $(15,17-21,30)$.

It is well established that with normal aging there are declines to muscle strength (40-42). Between the ages of 20 and 60, decreases between 35 and $45 \%$ have been reported for neck flexion and extension (43). Although there is limited data, it is likely that the general decline in neck strength continues into advanced age. The consequences of this progressive decline in neck strength may be particularly problematic for older adults at risk of falling. For example, with decreases in neck strength, older individuals may be unable to appropriately support their head during a fall leading to greater head acceleration at head impact and thus, have an increased risk of suffering a TBI.

\section{Neck Muscle Activation as Risk Factor for Fall-Related TBI}

It is important to note that not all empirical investigations of neck strength and head acceleration observed a strong association between these factors. Mihalik et al. (27) found that increased neck strength did not result in lower head acceleration during impact in youth ice hockey; this finding could potentially be 


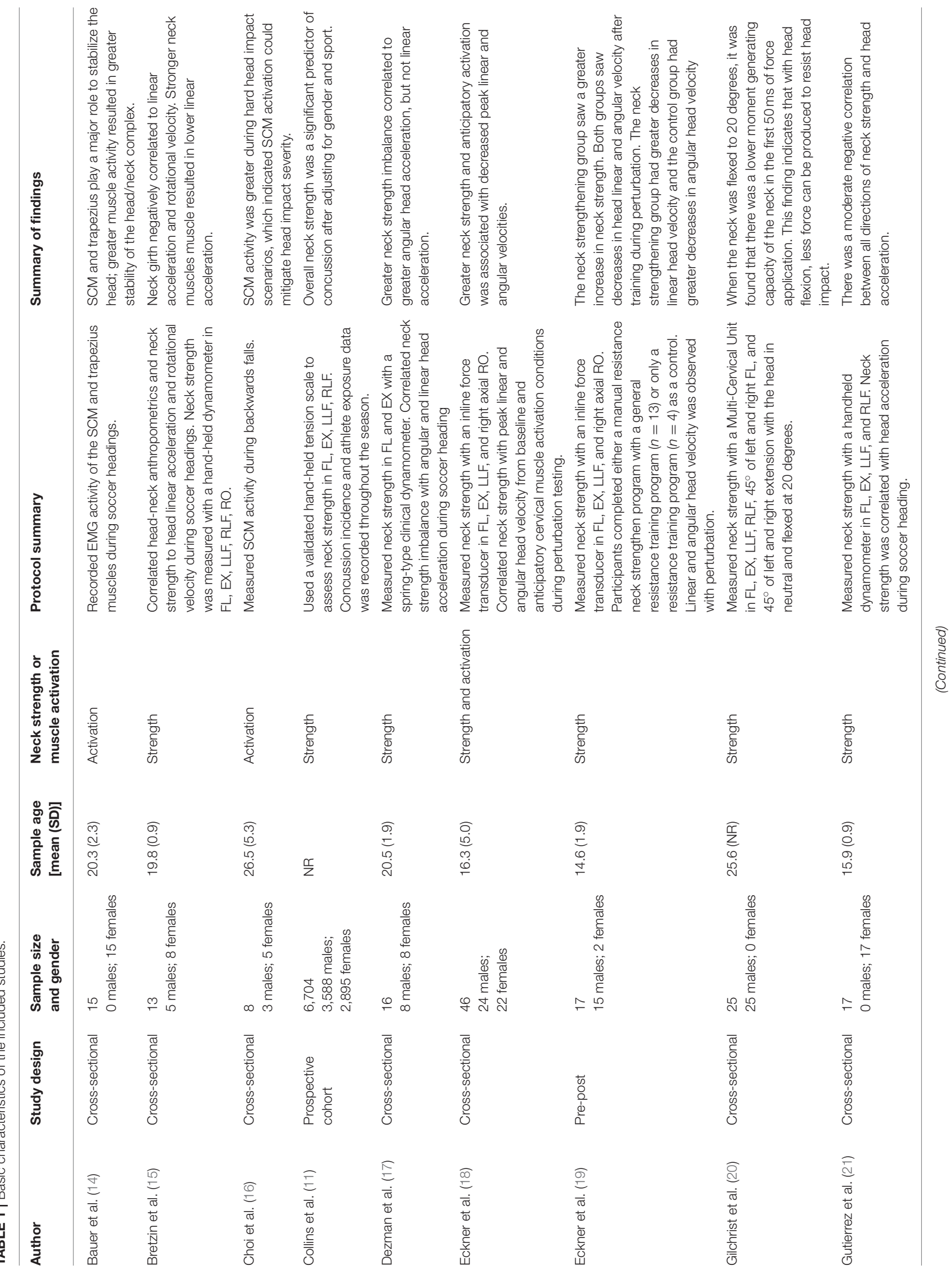




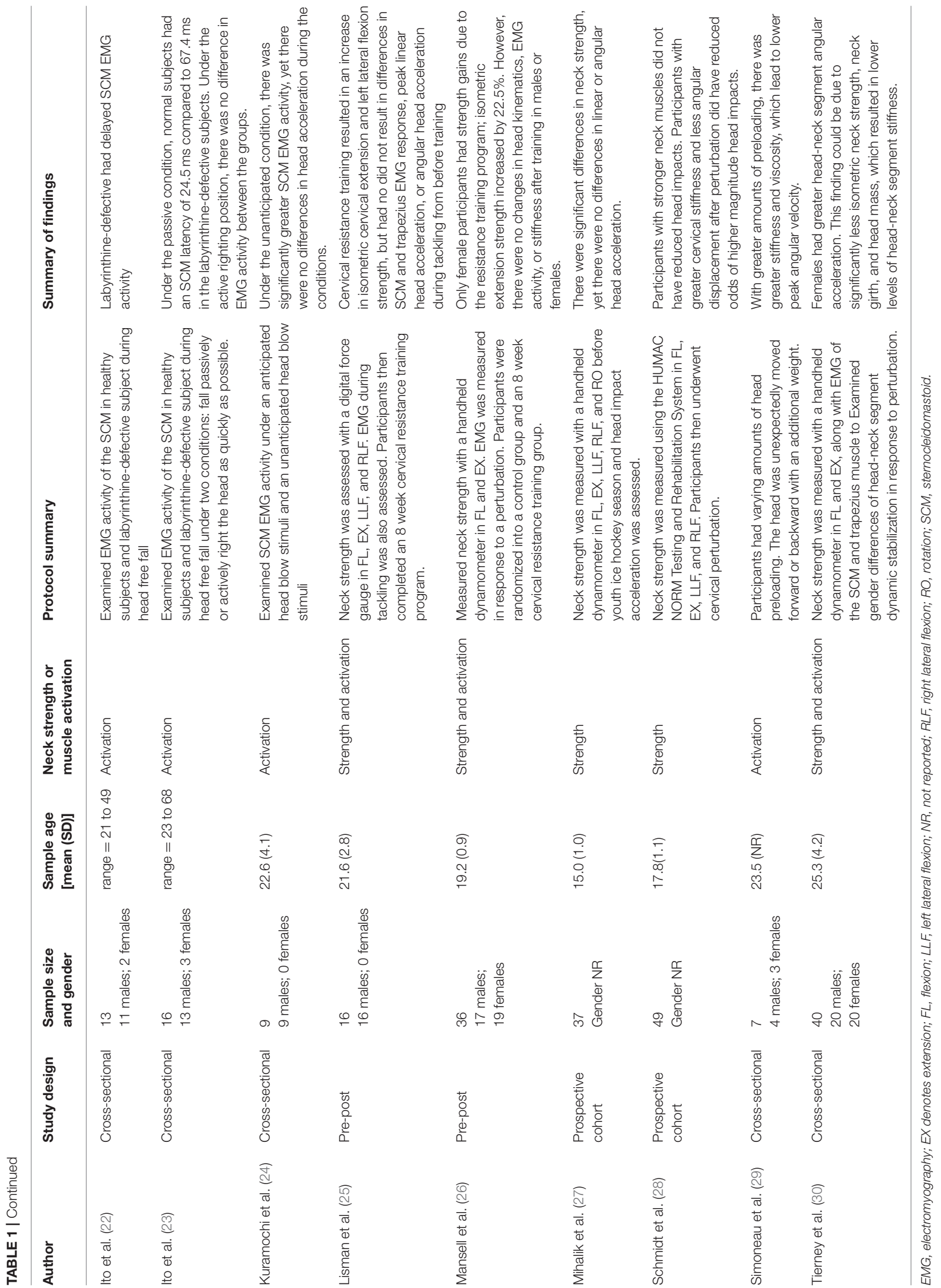


due to the age and competitive level of the sample. Conversely, Schmidt et al. (28) found that it was not neck strength, but neck stiffness that contributed to decreased injury risk. These finding highlights that neck strength alone may not fully characterize the neuromuscular control of the head necessary to mitigate head impact during a fall. It has been proposed that stabilization of the head during a perturbation results from the rapid activation of neck musculature to circumvent the perturbation, similar in context to whole body postural responses following external challenges to balance $(28,29,44)$.

Activation of the SCM and the upper trapezius muscles are important for head stabilization and reducing head impact severity in young adults $(14,16,22,23,28-30)$. A previous investigation specifically assessed the activation of the SCM muscles during simulated backwards falls in healthy young adults (16). For this study, participants fell under three different head control instructions. These were: (1) no impact-prevent the head from impacting the ground, (2) minimal impact-allow the head to impact the ground but with minimal force, and (3) hard impact-allow the head to impact the ground and inhibit efforts to reduce impact. During the no impact and minimal impact conditions, the SCM played a significant role in supporting the head. For the hard impact condition, the SCM was minimally active, which indicates that activation of the SCM most likely contributes to the prevention and modulation of head impact during a backward (16).

In young adults, the SCM has similar amounts of Type I and Type IIa muscle fibers (45). With aging, the composition of the SCM remodels to takes on a slower muscle phenotype (44-47). The area of fast twitch decrease and the number of slow twitch fibers increase, which result in slower SCM activation (44-47). Although there is limited data, it is logical to speculate that alterations to motor unit population occur in the splenius capitis and upper trapezius. The consequences of the age-related changes in neck muscle properties may mean that older adults react slower to external destabilizing perturbations. As a result, they are unable to quickly stabilize their head during a fall, which increases the possibility of TBI.

\section{Neck Strength and Muscle Activation Interventions}

Given the link between neck strength and head motion, several studies have examined the effectiveness of exercise programs targeting the muscles around the neck/head complex for improving overall head control. These previous investigations found mixed results. It was found that resistance training in college aged athletes did not alter EMG activity or head kinematics during impact $(25,26)$. Conversely, in a different adolescence sample, a resistance program successfully altered

\section{REFERENCES}

1. Taylor CA, Bell JM, Breiding MJ, Xu L. Traumatic brain injuryrelated emergency department visits, hospitalizations, and deaths United States, 2007 and 2013. MMWR Surveill Summ. (2017) 66:1-16. doi: $10.15585 / \mathrm{mmwr} . s s 6609 \mathrm{al}$ head kinematics during simulated impact (19). The differences observed in these studies may relate to the age and skill level of the participants. In addition to resistance training, it has also been suggested that neuromuscular training designed to enhance the neck muscles' dynamic responses to perturbation may be more beneficial than resistance training alone (28). While, resistance training has been showed to improve strength in upper and lower extremities in healthy older adults $(48,49)$, there is very limited empirical data pertaining to the efficacy of neck strength resistance programs in older adults. It remains to be seen if neck strength resistance programs can result in improvements in head control.

\section{FUTURE DIRECTIONS}

While the sports medicine literature highlights the potential implications of changes in neck strength and muscle activation patterns to mitigate head impact forces, these studies were primarily conducted on young healthy adults in relation to sport concussion. Although this body of research leads to the speculation that decreases in neck strength and muscle activation may be a significant contributor to fall-related TBIs in older adults, there are significant knowledge gaps. These knowledge gaps include age-related changes to neck muscle strength after the age of 75 years, age-related strength changes in all directions of motion, and age-related changes to muscle activation of the SCM, upper trapezius, and splenius capitis in response to a perturbation. It is also not clear if neck muscle strength or function is related to head acceleration in older adults. It should be further noted that obvious differences exist between the mechanics of sports concussion and those related to fall-induced TBIs. Consequently, more research is needed to understand the mechanisms of fall-related TBIs and the specific role of neck strength and muscle activation patterns for stabilization of the head during a fall in older adults. While promising, neck strength and muscle activation may together be described as a single factor in the multifactorial problem of fall-related TBIs. Other potential factors include polypharmacy, the use of antiarrhythmics, and unsafe bed or chair transfers (4). Investigations of the relationship between neck strength, muscle activation, and head acceleration during falls in older adults is warranted.

\section{AUTHOR CONTRIBUTIONS}

TW was the primary author who researched the background information and wrote the manuscript. SM helped to organize the manuscript and added information on age-related declines to the neck musculature. JS assisted in organizing the manuscript and added input throughout the manuscript. 
trends and risk factors. J Surg Res. (2015) 195:1-9. doi: 10.1016/j.jss.2015. 01.017

4. Hwang HF, Cheng CH, Chien DK, Yu WY, Lin MR. Risk factors for traumatic brain injuries during falls in older persons. J Head Trauma Rehabil. (2015) 30:E9-17. doi: 10.1097/HTR.0000000000000093

5. Murphy MP, Carmine H, Kolakowsky-Hayner S. Modifiable and nonmodifiable risk factors for falls after traumatic brain injury: an exploratory investigation with implications for medication use. Rehabil Nurs. (2014) 39:113-22. doi: 10.1002/rnj.89

6. Krishnamoorthy V, Distelhorst JT, Vavilala MS, Thompson H. Traumatic brain injury in the elderly: burden, risk factors, and prevention. J Trauma Nurs. (2015) 22:204-8; quiz E3-4. doi: 10.1097/JTN.0000000000000135

7. Yang Y, Mackey DC, Liu-Ambrose T, Leung PM, Feldman F, Robinovitch SN. Clinical risk factors for head impact during falls in older adults: a prospective cohort study in long-term care. J Head Trauma Rehabil. (2017) 32:168-77. doi: 10.1097/HTR.0000000000000257

8. McCrory P, Meeuwisse W, Dvorak J, Aubry M, Bailes J, Broglio S, et al. Consensus statement on concussion in sport-the 5(th) international conference on concussion in sport held in Berlin, October 2016. Br Journal Sports Med. (2017) 51:838-47. doi: 10.1136/bjsports-2017-097699

9. Langlois JA, Rutland-Brown W, Wald MM. The epidemiology and impact of traumatic brain injury: a brief overview. J Head Trauma Rehabil. (2006) 21:375-8. doi: 10.1097/00001199-200609000-00001

10. Scopaz KA, Hatzenbuehler JR. Risk modifiers for concussion and prolonged recovery. Sports Health. (2013) 5:537-41. doi: 10.1177/1941738112473059

11. Collins CL, Fletcher EN, Fields SK, Kluchurosky L, Rohrkemper MK, Comstock $\mathrm{RD}$, et al. Neck strength: a protective factor reducing risk for concussion in high school sports. J Prim Prev. (2014) 35:309-19. doi: 10.1007/s10935-014-0355-2

12. Huelke DF. Anatomy of the Human Cervical Spine and Associated Structures. SAE International (1979).

13. Netter FH. Atlas of Human Anatomy. 5th ed. Philadelphia, PA: Saunders Elsevier (2006).

14. Bauer JA, Thomas TS, Cauraugh JH, Kaminski TW, Hass CJ. Impact forces and neck muscle activity in heading by collegiate female soccer players. $J$ Sports Sci. (2001) 19:171-9. doi: 10.1080/026404101750095312

15. Bretzin AC, Mansell JL, Tierney RT, McDevitt JK. Sex differences in anthropometrics and heading kinematics among division I soccer athletes: a pilot study. Sports Health. (2017) 9:168-73. doi: 10.1177/1941738116678615

16. Choi WJ, Robinovitch SN, Ross SA, Phan J, Cipriani D. Effect of neck flexor muscle activation on impact velocity of the head during backward falls in young adults. Clin Biomech. (2017) 49:28-33. doi: 10.1016/j.clinbiomech.2017.08.007

17. Dezman ZD, Ledet EH, Kerr HA. Neck strength imbalance correlates with increased head acceleration in soccer heading. Sports Health. (2013) 5:320-6. doi: $10.1177 / 1941738113480935$

18. Eckner JT, Oh YK, Joshi MS, Richardson JK, Ashton-Miller JA. Effect of neck muscle strength and anticipatory cervical muscle activation on the kinematic response of the head to impulsive loads. Am J Sports Med. (2014) 42:566-76. doi: $10.1177 / 0363546513517869$

19. Eckner JT, Goshtasbi A, Curtis K, Kapshai A, Myyra E, Franco LM, et al. Feasibility and effect of cervical resistance training on head kinematics in youth athletes: a pilot study. Am J Phys Med Rehabil. (2018) 97:292-7. doi: 10.1097/PHM.0000000000000843

20. Gilchrist I, Moglo K, Storr M, Pelland L. Effects of head flexion posture on the multidirectional static force capacity of the neck. Clin Biomech. (2016) 37:44-52. doi: 10.1016/j.clinbiomech.2016.05.016

21. Gutierrez GM, Conte C, Lightbourne K. The relationship between impact force, neck strength, and neurocognitive performance in soccer heading in adolescent females. Pediatr Exerc Sci. (2014) 26:33-40. doi: $10.1123 /$ pes.2013-0102

22. Ito Y, Corna S, von Brevern M, Bronstein A, Rothwell J, Gresty M. Neck muscle responses to abrupt free fall of the head: comparison of normal with labyrinthine-defective human subjects. J Physiol. (1995) 489 (Pt 3):911-6. doi: 10.1113/jphysiol.1995.sp021103

23. Ito $\mathrm{Y}$, Corna S, von Brevern $\mathrm{M}$, Bronstein $\mathrm{A}$, Gresty $\mathrm{M}$. The functional effectiveness of neck muscle reflexes for head-righting in response to sudden fall. Exp Brain Res. (1997) 117:266-72. doi: 10.1007/s002210050221
24. Kuramochi R, Kimura T, Nakazawa K, Akai M, Torii S, Suzuki S. Anticipatory modulation of neck muscle reflex responses induced by mechanical perturbations of the human forehead. Neurosci Lett. (2004) 366:206-10. doi: $10.1016 /$ j.neulet.2004.05.040

25. Lisman P, Signorille JF, Del Rossi G, Asfour S, Eltoukhy M, Stambolian D, et al. Investigation of the effects of cervical strength training on neck strength, EMG, and head kinematics during a football tackle. Int J Sports Sci Eng. (2012) 6:131-40.

26. Mansell J, Tierney RT, Sitler MR, Swanik KA, Stearne D. Resistance training and head-neck segment dynamic stabilization in male and female collegiate soccer players. J Athl Train. (2005) 40:310-9.

27. Mihalik JP, Guskiewicz KM, Marshall SW, Greenwald RM, Blackburn JT, Cantu RC. Does cervical muscle strength in youth ice hockey players affect head impact biomechanics? Clin J Sport Med. (2011) 21:416-21. doi: 10.1097/JSM.0B013E31822C8A5C

28. Schmidt JD, Guskiewicz KM, Blackburn JT, Mihalik JP, Siegmund GP, Marshall SW. The influence of cervical muscle characteristics on head impact biomechanics in football. Am J Sports Med. (2014) 42:2056-66. doi: $10.1177 / 0363546514536685$

29. Simoneau M, Denninger M, Hain TC. Role of loading on head stability and effective neck stiffness and viscosity. J Biomech. (2008) 41:2097-103. doi: 10.1016/j.jbiomech.2008.05.002

30. Tierney RT, Sitler MR, Swanik CB, Swanik KA, Higgins M, Torg J. Gender differences in head-neck segment dynamic stabilization during head acceleration. Med Sci Sports Exerc. (2005) 37:272-9. doi: 10.1249/01.MSS.0000152734.47516.AA

31. Viano DC, Casson IR, Pellman EJ. Concussion in professional football: biomechanics of the struck player - Part 14. Neurosurgery. (2007) 61:313-27. doi: 10.1227/01.NEU.0000279969.02685.D0

32. Alsalaheen B, Bean R, Almeida A, Eckner J, Lorincz M. Characterization of cervical neuromuscular response to head-neck perturbation in active young adults. J Electromyogr Kinesiol. (2018) 39:70-6. doi: 10.1016/j.jelekin.2018.01.011

33. Almosnino S, Pelland L, Stevenson JM. Retest reliability of force-time variables of neck muscles under isometric conditions. J Athl Train. (2010) 45:453-8. doi: 10.4085/1062-6050-45.5.453

34. Axen K, Haas F, Schicchi J, Merrick J. Progressive resistance neck exercises using a compressible ball coupled with an air pressure gauge. J Orthop Sports Phys Ther. (1992) 16:275-80. doi: 10.2519/jospt.1992.16.6.275

35. Catenaccio E, Mu W, Kaplan A, Fleysher R, Kim N, Bachrach T, et al. Characterization of neck strength in healthy young adults. PM R. (2017) 9:884-91. doi: 10.1016/j.pmrj.2017.01.005

36. Lavallee AV, Ching RP, Nuckley DJ. Developmental biomechanics of neck musculature. J Biomech. (2013) 46:527-34. doi: 10.1016/j.jbiomech.2012.09.029

37. Tierney RT, Higgins M, Caswell SV, Brady J, McHard K, Driban JB, et al. Sex differences in head acceleration during heading while wearing soccer headgear. J Athl Train. (2008) 43:578-84. doi: 10.4085/1062-6050-43.6.578

38. Caswell SV, York M, Ambegaonkar JP, Caswell AM, Cortes N, Turner T. Neck strengthening recommendations for concussion risk reduction in youth sport. Int J Athl Ther Train. (2014) 19:22-7. doi: 10.1123/ijatt.2014-0043

39. Cornwell JrR. Creating a Standardized Program To Resistance Train The Muscles Of The Head And Neck. Virginia Polytechnic Institute and State University (2013).

40. Andersen JL, Terzis G, Kryger A. Increase in the degree of coexpression of myosin heavy chain isoforms in skeletal muscle fibers of the very old. Muscle Nerve. (1999) 22:449-54. doi: 10.1002/(SICI)1097-4598(199904)22:4\&1t;449::AID-MUS4\&gt;3.0.CO;2-2

41. Larsson L, Grimby G, Karlsson J. Muscle strength and speed of movement in relation to age and muscle morphology. J Appl Physiol Respir Environ Exerc Physiol. (1979) 46:451-6. doi: 10.1152/jappl.1979.46.3.451

42. Kallman DA, Plato CC, Tobin JD. The role of muscle loss in the agerelated decline of grip strength: cross-sectional and longitudinal perspectives. J Gerontol. (1990) 45:M82-8. doi: 10.1093/geronj/45.3.M82

43. Garces GL, Medina D, Milutinovic L, Garavote P, Guerado E. Normative database of isometric cervical strength in a healthy population. Med Sci Sports Exerc. (2002) 34:464-70. doi: 10.1097/00005768-20020300000013 
44. Woollacott MH, Shumway-Cook A, Nashner LM. Aging and posture control: changes in sensory organization and muscular coordination. Int J Aging Hum Dev. (1986) 23:97-114. doi: 10.2190/VXN3-N3RT-54JB-X16X

45. Meznaric M, Erzen I, Karen P, Cvetko E. Effect of ageing on the myosin heavy chain composition of the human sternocleidomastoid muscle. Ann Anat. (2018) 216:95-9. doi: 10.1016/j.aanat.2017.12.001

46. Kanekar N, Aruin AS. The effect of aging on anticipatory postural control. Exp Brain Res. (2014) 232:1127-36. doi: 10.1007/s00221-0143822-3

47. Bisdorff AR, Bronstein AM, Wolsley C, Gresty MA, Davies A, Young A. EMG responses to free fall in elderly subjects and akinetic rigid patients. J Neurol Neurosurg Psychiatry. (1999) 66:447-55. doi: 10.1136/jnnp.66.4.447

48. Borde R, Hortobagyi T, Granacher U. Dose-response relationships of resistance training in healthy old adults: a systematic review and metaanalysis. Sports Med. (2015) 45:1693-720. doi: 10.1007/s40279-015-0385-9
49. Cadore EL, Pinto RS, Bottaro M, Izquierdo M. Strength and endurance training prescription in healthy and frail elderly. Aging Dis. (2014) 5:183-95. doi: 10.14336/AD.2014.0500183

Conflict of Interest Statement: The authors declare that the research was conducted in the absence of any commercial or financial relationships that could be construed as a potential conflict of interest.

Copyright (c) 2019 Wood, Morrison and Sosnoff. This is an open-access article distributed under the terms of the Creative Commons Attribution License (CC BY). The use, distribution or reproduction in other forums is permitted, provided the original author(s) and the copyright owner(s) are credited and that the original publication in this journal is cited, in accordance with accepted academic practice. No use, distribution or reproduction is permitted which does not comply with these terms. 